\title{
ANALISIS KINERJA GAPOKTAN BERDASARKAN TINGKAT KEPUASAN ANGGOTA DAN KARYAWAN
}

\author{
RJ. Sihotang ${ }^{1 \mathrm{a}}$, A. Arsyad ${ }^{1}$ dan S. Masithoh ${ }^{1}$ \\ ${ }^{1}$ Jurusan Agribisnis, Fakultas Pertanian Universitas Djuanda Bogor \\ Jalan Tol Ciawi No. 1 Kotak Pos 35 Bogor 16720 \\ ${ }^{a}$ Korespondensi: Rio J Sitohang, E-mail: rio.jantinus@ unida.ac.id
}

\begin{abstract}
Gapoktan becomes the one of mainstay for the goverment on the things to approach the farmers directly. The research carried out at the Gapoktan of Rukun Tani with the aim of research to see the performance and the condition of environment, to know the performance of Gapoktan based on the satisfaction level of members and employees and to recommend the strategic steps of Gapoktan to increase the performance on the future. The research use the purposive sampling for the location and the respondents of research. Data collection method includes the primary data (the field observation and interviews using the questionary) and the secondary data (literature study). Data analyzed descriptively on the performance and environmental condition of Gapoktan. The performance analyzed based on the satisfaction level of employees and members of Gapoktan with using the analysis of Costumer Satisfaction Index (CSI), Importance Performance Analysis (IPA) and Service Quality and then processed with using the Microsoft excel 2010 and Software SPSS 22. Descriptively the strategic steps of Gapoktan based on the satisfaction level of employees and members against the Gapoktan has been recommended in this research. The performance of Gapoktan of Rukun Tani has the organization structure, the instrumen of organization, and the activity to support the development of Gapoktan. The performance of Gapoktan based on the satisfaction level of employees and members showed there were on the satisfied position on CSI value of 0.75 and 0.70 . However, there were still the anything that have to noticed by the Gapoktan. The IPA showed that the employees and members of Gapoktan have to increase the improvement and the yield of Service Quality analysis is still on the negative position. The strategic steps have to do to increase the loyality of members and employees of Gapoktan both in the facility equipment of employees and the socialization to the members of Gapoktan.
\end{abstract}

Key words: Performance, Satisfaction, CSI, IPA, Service Quality

\begin{abstract}
ABSTRAK
Gapoktan menjadi salah satu andalan bagi pemerintah dalam hal mendekati petani secara langsung. Penelitian ini dilakukan di Gapoktan Rukun Tani dengan tujuan penelitian ini untuk melihat keragaan dan kondisi lingkungan, mengetahui kinerja gapoktan berdasarkan tingkat kepuasan karyawan dan anggota serta merekomendasikan langkah strategis bagi gapoktan untuk peningkatan kinerja di masa mendatang. Metode penelitian ini dengan purvosive sampling untuk lokasi dan responden penelitian. Metode pengumpulan data meliputi data primer (observasi lapangan dan wawancara dengan kuisioner) dan data sekunder (studi literatur). Dianalisi secara deskriptif pada keragaan dan kondisi lingkungan gapoktan. Dilakukan analisi kinerja berdasarkan tingkat kepuasan karyawan dan anggota dengan menggunakan analisis Costumer Satisfaction Index (CSI), Importance Performance Analysis (IPA) dan Service Quality yang kemudian diolah dengan menggunakan Microsoft excel 2010
\end{abstract}


dan Software SPSS 22. Rekomendasi strategi dengan secara deskriptif berdasarkan kepuasan karyawan dan anggota terhadap Gapoktan, direkomendasikan berdasarkan penelitian ini. Hasil yang diperoleh keragaan Gapoktan Rukun Tani telah memiliki struktur organisasi dan perangkat organisasi dan adanya kegiatan yang menunjang perkembangannya. Kinerja Gapoktan berdasarkan karyawan dan anggota menunjukkan pada posisi puas pada nilai CSI 0,75 dan 0,70. Namun masih ada hal yang perlu diperhatikan oleh Gapoktan. Melihat hasil IPA menunjukkan dari karyawan dan anggota masih perlu adanya perbaikan dan hasil service Quality masih pada posisi negatif. Serta perlu adanya langkah strategis yang dilakukan dalam hal meningkatkan loyalitas anggota dan karyawan baik dalam pelengkapan fasillitas pada karyawan dan sosialisasi pada anggota Gapoktan.

Kata Kunci : Kinerja, Kepuasan, CSI, IPA, Service Quality

\section{PENDAHULUAN}

Berdasarkan struktur Pendapatan Domestik Bruto (PDB) Indonesia menurut lapangan usaha atas dasar harga berlaku triwulan II-2016 masih didominasi oleh tiga lapangan usaha yaitu : industri pengolahan sebesar $20,48 \%$, pertanian sebesar $14,32 \%$ dan perdagangan besar atau eceran sebesar $13,26 \%$. Sektor pertanian juga menjadi urutan teratas dalam hal penyerapan tenaga kerja, dapat dilihat pada tahun 2016 , dari 118,41 juta penduduk Indonesia terdapat 37,77 juta atau setara dengan $31,89 \%$ penduduk Indonesia yang bekerja di sektor pertanian (Badan Pusat Statistik, 2016).

Keberadaan kelembagaan di bidang agribisnis memiliki fungsi eksternal dan internal. Fungsi eksternal menjelaskan bagaimana dan siapa yang akan berhubungan dengan pihak luar sedangkan pada fungsi internal menjelaskan bahwa kelembagaan menjadi pedoman bagi anggotanya (Septian, 2010). Berdasarkan Peraturan Menteri Pertanian Republik Indonesia nomor 67/ permentan/ SM.050/ 12/ 2016 tentang pembinaan kelembagaan pertanian, kelembagaan pertanian terdiri atas kelompok tani, gabungan kelompok tani, asosiasi komoditas pertanian dan dewan komoditas pertanian nasional.

Gapoktan menjadi salah satu andalan bagi pemerintah dalam hal menggapai petani secara langsung. Gapoktan diharapkan dapat memenuhi fungsi dari sisi sarana produksi, pemasaran, permodalan sekaligus informasi bagi petani (Syahyuti, 2007).

Pengukuran kinerja gapoktan sebagai salah satu bagian dari pemerintah perlu dilakukan baik dari segi Sumber Daya Manusia (SDM) dan pelanggan (anggota) baik berdasarkan tingkat kepentingan dan kepuasan karyawan dan anggota terhadap kinerja pelayanan gapoktan khususnya Gapoktan Rukun Tani, dalam rangka menunjang fungsi gapoktan sebagai andalan pemerintah dalam menggapai petani secara langsung dengan fungsi sebagai lembaga yang mempermudah aksebilitas petani terhadap informasi dalam rangka menunjang kegiatan usahatani dan lembaga ekonomi di tingat petani.

Saat ini pemerintah secara langsung menggapai para petani dengan menggunakan peran gapoktan sebagai lembaga yang mempermudah aksesibilitas petani terhadap informasi dan lembaga ekonomi dan finansial di tingkat petani dalam hal pengembangan pertanian.

Melihat dari perkembangan gapoktan saat ini seharusnya diikuti oleh perkembangan pelayanan gapoktan kearah yang leih baik. Melihat banyak gapoktan yang memiliki kendala dari segi SDM atau sumber daya modal, sehingga menyebabkan gapoktan tidak dapat menjalankan usahanya secara maksimal.

Gapoktan Rukun Tani menjadi salah satu lembaga yang bertujuan untuk meningkatkan kesejahteraan aggotanya dengan memberikan berbagai fasilitas dan 
pelayanan yang dapat diakses petani anggota dalam memperlancar usahanya, namun dalam pelaksanaan usahanya masih ada anggota yang tidak langsung menjual hasil panen kepada Gapoktan serta belum adanya penilaian nyata tentang bagaimana kinerja Gapoktan dilihat dari segi non-finansial melalui tingkat kepuasan anggota dan karyawan.

Penelitian ini bertujuan untuk mendeskripsikan keragaan dan kondisi lingkungan Gapoktan Rukun Tani serta mempelajari kinerja Gapoktan Rukun Tani berdasarkan tingkat kepuasan anggota dan karyawan sehingga dapat dirumuskan rekomendasi langkah-langkah strategis bagi Gapoktan Rukun Tani dalam meningkatkan kinerja di masa yang akan datang.

\section{BAHAN DAN METODE}

Penelitian ini dilaksanakan di Gapoktan Rukun Tani tepatnya di Desa Citapen, Kecamatan Ciawi Kabupaten Bogor. Penentuan lokasi secara purposive sampling. Waktu penelitian dilaksanakan dari bulan Juli - Desember 2018.

Data yang dikumpulkan dalam penelitian ini yaitu data primer dan data sekunder. Data primer diperoleh melalui observasi di lapangan serta wawancara dengan menggunakan kuisioner. Data primer ini mengenai profil, jenis usaha dan penunjang lainnya. Data sekunder diperoleh dari literatur seperti penelitian terdahulu, buku-buku dan jurnal ilmiah (Umar, 2002)

Metode pengambilan responden dengan menggunakan purposive sampling atau penetapan dengan pertimbangan tertentu (Sugiyono, 2016). Penetapan yang dilakukan bahwa responden merupakan anggota dan karyawan Gapoktan Rukun Tani. Jumlah responden yang digunakan dalam penelitian ini mengacu berdasarkan pendapat Umar (2004) pengukuran sampel yang diterima berdasarkan metode penelitian minimal 30 sampel, sehingga pada penelitian ini total keseluruhan resonden sebanyak 70 responden dengan ketentuan 35 orang anggota dan 35 orang karyawan Gapoktan Rukun Tani.

\section{Metode Analisis Data Analisis Deskriptif}

Metode ini berfokus pada fenomena sosial, hal ini didasarkan pada kepercayaan bahwa pengetahuan dihasilkan dari setingan sosial dan pemahaman pengetahuan soasial adalah proses ilmiah yang sah (Emzir, 2016).

Pada analisis ini digunakan untuk menganalisis keragaan dan kondisi lingkungan Gapoktan Rukun Tani dan rekomendari langkah strategis Gapoktan Rukun Tani dilihat dari kondisi yang ada pada saat penelitian.

\section{Analisis Costumer Satisfaction Index (CSI)}

Analisis ini untuk mengetahui tingkat kepuasan pelanggan/ anggota dan karyawan dengan mempertimbangkan harapan/ kepentingan dan kinerja/ kepuasan dari atribut yang menggunakan skala likert. Skala likert yang digunakan adalah akala $1-5$ dengan pengukuran dapat diukur dengan langkah berikut :

a. Menentukan Mean Importance Score (MSI) berdasarkan rata-rata kepentingan setiap responden.

$\mathrm{MIS}=\frac{\left(\begin{array}{c}n \\ i=1\end{array} y i\right)}{n}$

Keterangan :

$\mathrm{n}=$ Responden

$\mathrm{Yi}=$ Nilai kepentingan atribut $\mathrm{Y}$ ke i

b. Membuat Weigt Factors (WF) yang merupakan persentase nilai MIS per atribut terhadap total MIS seluruh atribut.

$\mathrm{WF}=\frac{M I S i}{p_{i=1}^{p} M I S i} \times 100 \%$

Keteragan:

$\mathrm{p}=$ Atribut Kepentingan ke $-\mathrm{p}$ 
c. Membuat Weight Score (WS) yang merupakan perkalian antara WF dan rata-rata tingkat kepuasan (MSS).

$$
\text { Wsi }=\text { Wfi } \times \text { MSS }
$$

\section{d. Menentukan CSI}

$$
\mathrm{CSI}=\frac{p_{i=1}^{p} W s i}{H S} \chi 100 \%
$$

Keterangan:

$\mathrm{p}=$ Atribut kepentingan ke-p

$\mathrm{HS}=$ Skala Maksimum yang digunakan.

Penentuan tingkat kepuasan anggota dan karyawan dapat dilihat dari kriteria CSI. Berdasarkan pendapat Simamora (2002) pada tabel 1.
Tabel 1 Kriteria penilaian CSI

\begin{tabular}{cc}
\hline Nilai CSI & Kriteria CSI \\
\hline $0,00-0,20$ & Sangat tidak puas \\
$0,21-0,40$ & Tidak Puas \\
$0,41-0,60$ & Cukup Puas \\
$0,61-0,80$ & Puas \\
$0,81-1,00$ & Sangat Puas \\
\hline Sumber : Simamora, 2002 &
\end{tabular}

\section{Analisis Importance Performance Analysis (IPA)}

Pada analisis ini merupakan teknik penerapan yang mudah dalam mengukur atribut dari tingkat kepentingan dan kinerja yang berguna untuk pengembangan ke depannya (Pratama, 2016)

Pada penelitian ini akan disajikan pengukuran IPA pada anggota dan karyawan yang akan disajikan dalam bentuk diagram kartesius pada gambar 1 berikut

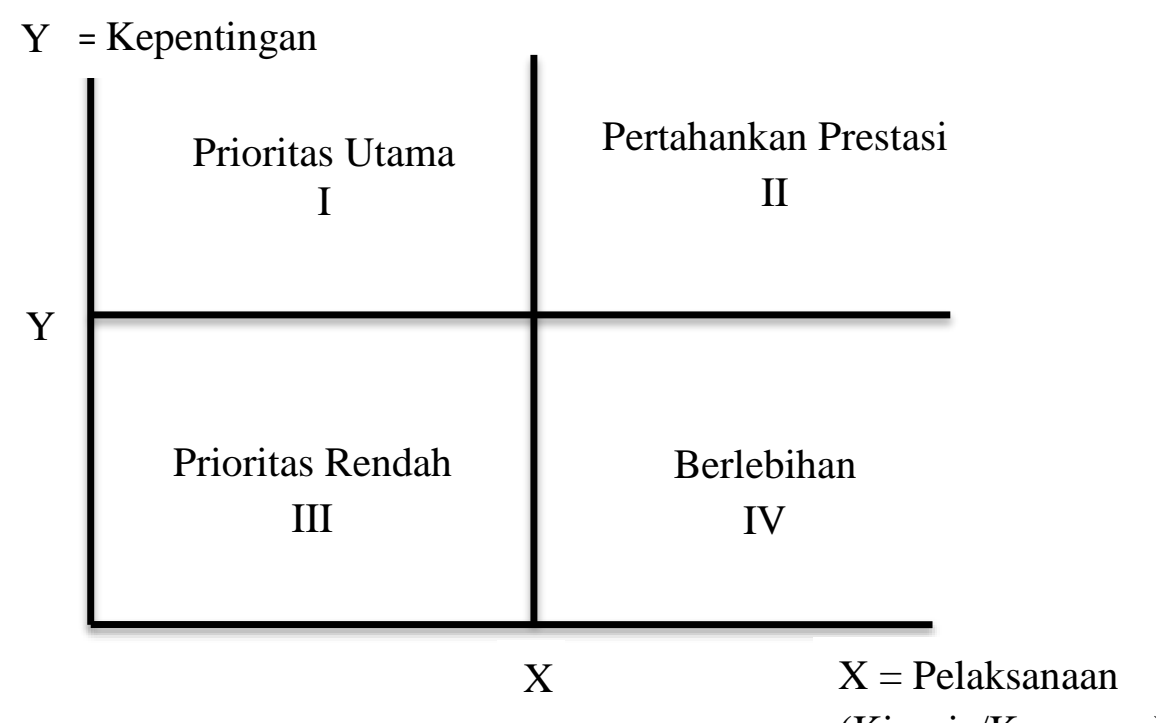

(Kinerja/Kepuasan)
Untuk lebih jelasnya adapun interperstasi dari tiap kuadran sebagai berikut :

1. Kuadran I pada kuadran ini ada beberapa faktor yang dianggap penting tetapi kinerja masih dinilai belum memuaskan sehingga perlu untuk memperbaharui guna meningkatkan performa yang ada pada kuadran ini.

2. Kuadran II pada kuadran ini ada faktor-faktor yang dianggap penting dan diharapkan sebagai penunjang kepuasan sehingga prestasi wajib dipertahankan. 
3. Kuadran III pada kuadran ini ada faktor-faktor yang dianggap memiliki kinerja aktual yang rendah dan tidak terlalu penting atau tidak terlalu diharapkan sehingga tidak perlu memprioritaskan pada faktor tersebut.

4. Kuadaran IV pada kuadran ini ada faktor yang dianggap tidak terlalu penting dan tidak terlalu diharapkan sehingga perlu dialokasikannya biaya pada faktor ini kepada faktor lain yang memiliki prioritas lebih lagi.

\section{Analisis Service Quality}

Analisis ini merupakan skala ringkas namun memiliki tingkat kebenaran dan kepercayaan cukup tinggi, digunakan analisis ini agar lebih mengerti kepentingan dan kepuasan terhadap pelayanan yang diberikan (Pohandry, 2013). Pada penelitian ini digunakan untuk menghitung skor service quality pendapat anggota dan karyawan terhadap Gapoktan Rukun Tani, diperoleh dari kepuasan yang diterima anggota dan karyawa dikurangi dengan nilai kepentingan atau harapan. Adapun rumus perhitungannya sebagai berikut :

Keterangan :

$$
Q=P-E
$$

$\mathrm{Q}=$ Quality Of Service (Kualitas Pelayanan) $\mathrm{P}=$ Perceived Service (Persepsi/kepuasan)

$\mathrm{E}=$ Expectasi $($ Harapan/kepentingan

\section{HASIL DAN PEMBAHASAN}

\section{Karakteristik Responden}

\section{Karakteristik Karyawan}

Karakteristik responden pada karyawan meliputi jenis kelamin, usia, lama bekerja dan tingkat pendidikan. Dari hasil yang diperoleh berdasarkan usia karyawan di dominasi oleh usia $51-60$ tahun sebanyak 29\% dengan jenis kelamin paling banyak adalah perempuan sebanyak 20 orang dengan persentase $57 \%$ dengan lama bekerja di gapoktan paling besar 7 12 tahun pada persentase $69 \%$ dengan jumlah 24 orang serta tingkat pendidikan mayoritas adalah tidak tamat SD sebanyak 57\% sebanyak 20 orang.

\section{Karakteristik Anggota}

Karakteristik responden anggota pada penelitian ini meliputi jenis kelamin yang myoritas adalah laki-laki sebanyak $77 \%$ atau 27 orang, rentang usia paling besar 41 - 50 tahun sebanyak 11 orang dengan persentase $31 \%$, pendidikan responden paling banyak adalah tamatan SD sebanyak 18 orang dengan persentase $52 \%$, pekerjaan utama mayoritas adalah seorang petani, dengan pendapatan per bulan paling banyak adalah > Rp 1.000 .000 - Rp 2.000.000 per bulan dengan jumlah 16 orang persentese $46 \%$, dengan pengalaman bertani tertinggi $0-10$ tahun sebanyak 20 orang atau setara dengan $57 \%$, dengan luas lahan garapan terbanyak adalah $0-5.000 \mathrm{~m}^{2}$ sebanjak 22 orang atau setara dengan $63 \%$ dan dengan jumlah tanggungan keluarga paling tinggi $0-5$ orang sebanyak 31 orang setara dengan $89 \%$ dan lama bergabung dengan gapoktan paling banyak $6-10$ tahun sebanyak 24 orang setara dengan $69 \%$.

Variasi pendapatan keluarga tergantung pada beberapa faktor antara lain hubungan dengan penguasaan lahan garapan, jenis usaha dan pekerjaan tambahan dari sektor pertanian atau non pertanian (Kurniasih, 2017).

\section{Analisis Costumer Statisfacyion Index}

\section{Analisis CSI berdasarkan karyawan gapoktan.}

Pada analisis CSI ini memberikan hasil rata-rata kepentingan atau harapan pada seluruh indikator sebesar 4,13 dan rata-rata kepuasan sebesar 3,75. Hasil dari perhitungan CSI menunjukkan tingkat kepuasan karyawan terhadap gapoktan berada pada posisi puas dimana hasil yang diperoleh sebesar 0,75 , hal ini mengacu pada tingkat penilaian CSI pada rentang 0,61 - 0,80 dengan kritera CSI dalam posisi puas. Pada kesempatan ini perlu adanya alokasi pengurus dalam hal meningkatkan kepuasan karyawan untuk 
bekerja pada gapoktan agar tercapai predikat sangat puas.

\section{Analisis CSI berdasarkan anggota gapoktan}

Hasil yang diperoleh berdasarkan analisis CSI pada anggota ini. Rata-rata tingkat kepentingan pada seluruh dimensi pada indikator memiliki nilai 4,07 dengan rata-rata tingkat kepuasan seluruh dimensi pada seluruh indikator sebesar 3,51. Berdasarkan pengukuran CSI hasil yang diperoleh sebesar 0,70 dimana hasil ini menunjukkan tingkat kepuasan anggota berdasarkan kriteria penilaian CSI pada rentang 0,61 - 0,80 berada pada kriteria CSI pada posisi puas. Sehingga hasil penilaian menggunakan CSI anggota sudah merasa puas dengan kinerja palayanan gapoktan terhadap anggota.

\section{Analisi Importance Performance Analysis}

\section{Analisis IPA kepuasan karyawan terhadap kinerja gapoktan}

Pada analisis ini melihat sejauh mana tingkat kepuasan karyawan terhadap kinerja Gapoktan Rukun tani dan juga melihat persebaran prioritas yang diinginkan karyawan. Gambar 3 diagram kartesius analisis IPA pada kayawan.

Dari hasil digram kartesius maka diperoleh penjabaran sebagai berikut :

\section{Kuadran I}

Pada kuadran ini, indikator dianggap oleh karyawn penting namun tingkat kinerja/kepuasan belum sesuai. Dalam kuadran ini terdiri dari :
(2) Kesesuaian bonus dan insentif yang dibeikan Gapoktan.

(8) Gapoktan memeberikan manfaat dalam kesejahteran karyawan

\section{Kuadran II}

Pada kuadran ini, menunjukkan tingkat kepuasan telah sesuai dengan kepentingan yang diharapkan karyawan. Dalam kuadran ini terdiri dari :

(9) Kejelasan memberikan informasi pada karyawan.

(11)Jaminan gapoktan terhadap kesehaan dan keselamatan karyawan.

(12) Perhatian dari atasan.

(13)Kemudahan berkomunikasi dengan atasan

\section{Kuadran III}

Pada kuadran ini indikator dinilai kurang penting oleh karyawan dan pada kenyataannya kepuasan pada kuadran ini biasa-biasa saja. Yang tergabung dalam kuadran ini sebagai berikut :

(1)Kesesuaian gaji yang diberikan gapoktan

(3)Kelengkapan fasilitas untuk mendukung pekerjaan

(6)Penilaian terhadap kinerja karyawan

(10)kecepatan gapoktan dalam menanggapi permasalah karyawan.

\section{Kuadran IV}

Pada kuadran ini indikator dianggap kurang penting oleh karyawan namun tingkat kepuasan sudah sangat baik. Yang tergabung dalam kuadran ini adalah :

(4) Kenyamanan ditempat kerja.

(5) Fleksibilitas peraturan di tempat kerja

(7)Kemudahan berkomunikasi dengan karyawan lain. 


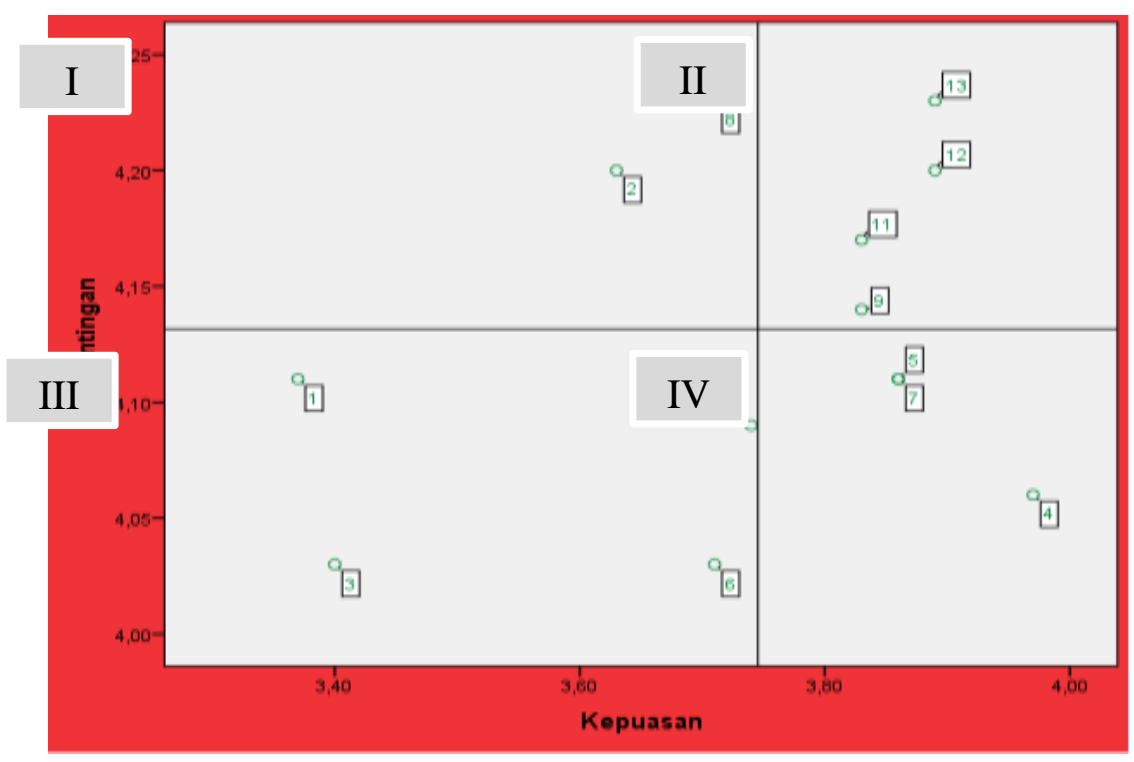

Gambar 3 Diagram Kartesius pada Karyawan

\section{Analisis IPA Pada Kepuasan Anggota Terhadap Kinerja Gapoktan}

Hal ini digunakan untuk melihat prioritas yang paling dibutuhkan anggota dan tingkat kepuasannya. Diagram Kartesius disajikan pada Gambar 4.

Pada gambar dijelaskan bahwa indikator yang masuk pada tiap kuadran yakni :

\section{Kuadran I}

Indikator pada kuadran ini dintaranya :

(6) Kecepatan dan ketanggapan pelayanan gapoktan

(8) Pengetahuan dan pelayanan yang baik dari pengurus

(9)Keberadaan gapoktan dalam mamasarkan hasil produk anggota

(14) Kedekatan jarak anggota dengan lokasi gapoktan.

\section{Kuadran II}

Indikator pada kuadran ini diantaranya :

(1)Kemudahan dalam proses pendaftaran anggota baru.

(2) Kemudahan dalam melakukan simpan pinjam.
(4) Kesigapan pengurus dalam menanggapi permasalahan anggota.

(5) Kesigapan pengurus dalam menanggapi permasalahan anggota

(13) Transparansi keuangan

(16) Kejujuran karyawan pada saat melakukan pembayaran.

\section{Kuadran III}

Indikator pada kuadran ini diantaranya :

(7)Kemampuan pelayanan gapoktan terhadap anggota.

(12)Perhatian pengurus terkait kepentingan anggota.

(15)Kemudahan anggota dalam pembelian saprodi.

(17)Kecepatan dalam penyediaan alat pertanian.

\section{Kuadran IV}

Indikator pada kuadran ini diantaranya :

(3) Kesesuaian pengajuan pinjaman dengan realisasi

(10) Kemudahan berkomunikasi antara pengurus dengan anggota.

(11) Ketersediaan waktu yang diberikan pengurus terhadap anggota. 


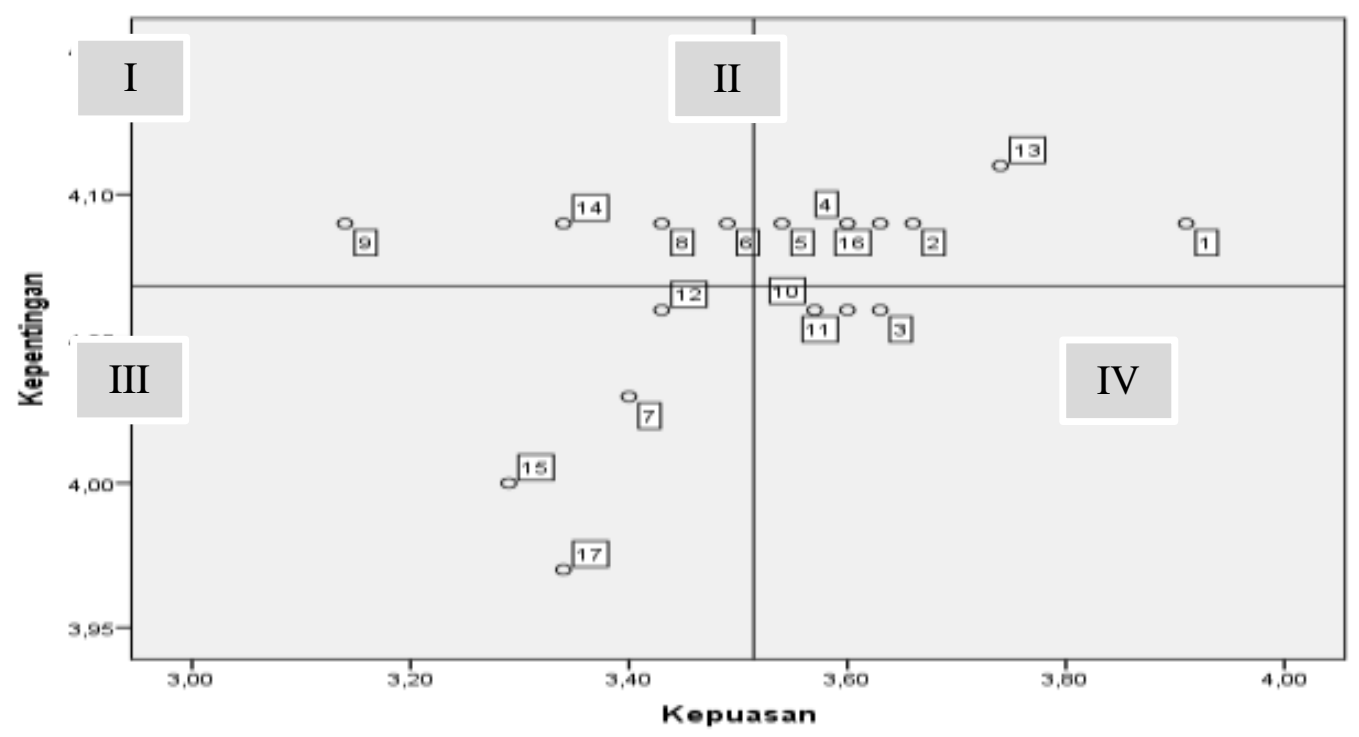

Gambar 4 Diagram kartesius pada anggota

\section{Analisis Service Quality}

Pada analisis ini digunakan untuk menghitung selisisih antara kepuasan atau kinerja dengan kepentingan atau harapan. Analisis ini digunakan pada anggota dan karyawan. Hasil dari analisis ini menunjukkan bahwa pada karyawan dari ke 13 indikator semuanya memiliki nilai kesenjangan yang bernilai negtif.

Sedangkan analisis service quality pada anggota menunjukkan hasil dari 17 indikator semua memiliki nilai GAP atau kesenjangan yang bernilai negatif.

\section{Langkah Strategis Perbaikan Kinerja}

Berdasarkan hasil pengukuran kinerja yang telah dilakukan baik pengukuran kinerja dari karyawan dan anggota. Ada beberapa hal yang harus dilakukan oleh Gapoktan/pengurus antara lain :

1. Hasil dari CSI menunjukkan bahwa tingkat kepuasan karyawan berada pada posisi puas pada nilai sebesar 70 namun pada kenyataannya berdasarkan hasil IPA dari 13 indikator masih ada 9 indikator yang harus diperbaharui oleh Gapoktan. Dalam hal ini perbaikan yang harus dilakukan oleh Gapoktan adalah mengacu pada kuadran I dimana pada kuadran ini indikator dinilai penting bagi karyawan namun tingkat kepuasan atau kinerja yang dirasakan karyawan belum sesuai. Langkah strategis yang harus dilakukan Gapoktan dilihat dari nilai kesenjangan Gapoktan adalah lebih menaikkan gaji karyawan dan menambahkan bonus yang di peroleh serta melakukan kelengkapan fasilitas yang mendukung pekerjaan karyawan sehingga karyawan semakun loyal bekerja kepada Gapoktan.

2. Pada anggota Gapoktan berdasarkan hasil CSI nilai yang didapat menunjukkan bahwa anggota puas dengan kinerja Gapoktan. Namun pada kenyataanya masi terdapat 11 indikator yang harus diperbaiki khususnya pada indikator yang masuk pada kuadran I pada analisis IPA. Langkah strategis yang harus dilakukan dilihat dari nilai kesenjangan adalah perlunya Gapoktan meingkatkan posisi tawar dari hasil produksi anggota atau harga beli yang lebih baik sehingga anggota mau melakukan penjualan hasil panen atau produksi kepada Gapoktan secara langsung. Kemudian perlu dilakukannya sosialisasi kepada anggota melihat jarak menjadi salah satu alasan terjadinya kesenjangan sehingga anggota enggan untuk melakukan transaksi secara langsung terhadap Gapoktan. Ketersediaan dan kecepatan serta pemberian harga miring terhadap penjualan sarana produksi perlu 
dilakukan oleh Gapoktan mengingat adanya anggapan dari beberapa anggota pembelian saprodi di Gapoktan harus menunggu proses serta harga yang di tawarkan lebih mahal dari harga toko. Serta perlunya pengetahuan dan pelayanan yang baik dari karyawan maupun pengurus.

\section{KESIMPULAN DAN SARAN}

\section{Kesimpulan}

Berdasarkan hasil analisis yang dilakukan mengenai tingkat kepuasan kinerja Gapoktan Rukun Tani terkait kepuasan anggota dan karyawan dapat disimpulkan sebagai berikut :

1. Gapoktan Rukun Tani telah melaksanakan fungsi sebagai Gapoktan. Dengan beberapa perangkat organisasi yang bekerja sama baik dalam hal pengembangan usaha dan tanggungjawab baik dalam hal pertanggungjawaban pada saat pelaksanaan rapat anggota. Pelaksanaan fungsi Gapoktan ini telah berjalan dilihat dari unit usaha yang dilaksanakan baik itu unit usaha produksi, pemasaran, sarana produksi, alsintan dan permodalan atau simpan pinjam. Hal ini mengacu pada fungsi Gapoktan berdasarkan Peraturan Mentri Pertanian yang mengemban tanggungjawab dalam hal kepentingan anggotanya. Gapoktan ini sangat berpotensi baik dalam hal pengembangan unit usaha yang telah dijalankan oleh Gapoktan.

2. Karyawan dan anggota merasa puas terhadap kinerja Gapoktan. Namun dalam pengembangannya masih ada yang perlu dibenahi oleh Gapoktan dilihat dari indikator yang dianalisis dengan IPA dan Service Quality baik itu pada karyawan dan anggota. Dimana perbaikan dapat dilihat dari tingkat kepentingan dan nilai kesenjangan yang menunjukkan perlu adanya perbaikan pada tiap indikator pada karyawan maupun anggota dengan nilai kesenjangan keseluruhan negatif.
Dengan perbaikan paling diutamakan adalah posisi kuadran pada IPA dan nilai kesenjangan negatif paling besar yang dihasilkan.

3. Langkah strategis perbaikan kinerja pada Gapoktan adalah perlunya meningkatkan loyalitas karyawan dan melaukan sosialisasi dalam hal meningkatkan minat anggota untuk melakukan transakasi kepada Gapoktan. Hal ini pada loyalitas karyawan dengan cara meningkatkan gaji dan bonus serta memfasilitasi kelengkapan alat kerja sedangkan pada anggota perlu peningkatan posisi tawar terhadap pebelian produk anggota.

\section{Implikasi Kebijakan}

1. Meskipun secara garis besar tingkat kepuasan anggota dan karyawan terhadap kinerja Gapoktan Rukun Tani berada pada posisi puas. Namun perlu dilaksanakan sosialisasi baik itu mengenai informasi dan mengenai sarana produksi dari Gapoktan agar anggota lebih mau berinteraksi kepada Gapoktan baik dalam pembelian saprodi dan peningkatan usaha anggota.

2. Untuk penelitian selanjutnya diharapkan dapat menggunakan sistem penilaian kinerja berdasarkan faktor internal dan eksternal pada Gapoktan. Baik itu berdasarkan finansial, kemampuan intelektual, keperibadian, budaya dan lingkungan sosial ataupun hubungannya dengan peraturan yang dilaksanakan oleh Gapoktan serta kontribusi pemerintah terhadap Gapoktan.

\section{Daftar Pustaka}

Pohandry, Arie. 2013. Analisis Tingkat Kepuasan Pelanggan Dengan Menggunakan Metode Customer Satisfaction Index dan Importance Performance Analysis Serta Service Quality. Jurnal REKAVASI. Vol : 1, No1, halaman 21-29.

Badan Pusat Statistik. 2016. Keadaan Ketenaga Kerjaan Agustus 2016. 
www.bps.go.id. Diakses pada 15 Februari 2018.

Badan Litbang Pertanian, Kementrian Pertanian Republik Indonesia. 2016. Peraturan Mentri Pertanian Republik Indonesia Nomor 67/Permentan/SM.050/ 12/ 2016.. http:// www.litbang.pertanian.go.id. Diakses pada 1 Juli 2018.

Dian Kencana Ayudhia. 2008. Analisis Hubungan Sistem Penilaian Kinerja Dengan Motivasi Kerja dan Kepuasan Kerja Karyawan (Studi Kausus Karyawan PT. X Tbk. Bogor). [Skripsi]. Bogor : Fakultas Ekonomi dan Manajeman Institut Pertanian Bogor.

Emzir. 2016. Metodelogi Penelitian Kualitatif Analisis Data. Jakarta : Rajawali Press.

Manyamsari, Ira. 2014. Karakteristik Petani dan Hubungannya Dengan Kompetensi Petani Lahan Sempit. Agrisep vol (15) No $2: 58-74$

Pratama, Leonardi. 2016. Analisis Kepuasan dan Strategi Pengembangan Koperasi (Studi Kasus Koperasi Kredit Sehati
Jakarta). [Tesis]. Bogor : Sekolah Pascasarjana Institut Pertanian Bogor.

Septian D. 2010. Peran Kelembagaan Kelompok Tani Terhadap Produksi dan Pendapatan Petani Ganyong di Desa Sindanglaya Kecamatan Sukamantri Kabupaten Ciamis Jawa Barat [Skripsi]. Bogor : Institut Pertanian Bogor.

Simamora B. 2002. Panduan Riset Perilaku Konsumen. Jakarta : PT. Gramedia Pustaka Utama

Sugiyono. 2016. Metode Penelitian Kuantitatif, Kualitatif dan $R \& D$ Cetakan 12. Bandung : Penerbit Alfabet

Syahyuti. 2007. Penerapan Pendekatan Pemberdayaan dalam Kegiatan Pembangunan Pertanain: Perbandingan Kegatan P4K, PIDRA, P5MI dan Prima Tani. Forum Penelitian Agro Ekonomi. Vol. 25. No.2:104-166

Umar, Husain. 2002. Strategic Manageman In Action, Cetakan Kedua. Jakarta : PT Gramedia Pustaka Utama. 
Lampiran 1. Karakterisik Responden Karyawan

\begin{tabular}{ccc}
\hline Karakteristik & Jumlah (orang) & Persentase (\%) \\
\hline Jenis Kelamin & 15 & 43 \\
Laki-laki & 20 & 57 \\
Perempuan & 3 & \\
\hline Usia (tahun) & 10 & 28 \\
$21-30$ & 8 & 23 \\
$31-40$ & 10 & 29 \\
$41-50$ & 2 & 6 \\
$51-60$ & 2 & 6 \\
$61-70$ & 11 & 31 \\
$71-80$ & 24 & 69 \\
\hline Lama Bekerja (tahun) & & \\
$7-12$ & 20 & 57 \\
Pendidikan & 13 & 37 \\
Tidak Tamat SD & 1 & 3 \\
Tamat SD/MI/Sederajat & 1 & 3 \\
Tamat SMP/MTS/Sederajat & 10 &
\end{tabular}

Sumber :Data primer diolah, 2018 
Lampiran 2. Karaktersistik responden anggota

\begin{tabular}{|c|c|c|}
\hline Karakteristik & Jumlah (orang) & Persentase $(\%)$ \\
\hline \multicolumn{3}{|l|}{ Jenis Kelamin } \\
\hline Laki-laki & 27 & 77 \\
\hline Perempuan & 8 & 23 \\
\hline \multicolumn{3}{|l|}{ Usia Responden (tahun) } \\
\hline $20-30$ & 5 & 14 \\
\hline $31-40$ & 9 & 26 \\
\hline $41-50$ & 11 & 31 \\
\hline $51-60$ & 5 & 14 \\
\hline $61-70$ & 3 & 9 \\
\hline $71-80$ & 1 & 3 \\
\hline $81-90$ & 1 & 3 \\
\hline \multicolumn{3}{|l|}{ Pendidikan } \\
\hline Tidak tamat SD & 4 & 11 \\
\hline Tamat SD/Sederajat & 18 & 52 \\
\hline Tamat SMP/Sederajat & 7 & 17 \\
\hline Tamat SMA/Sederajat & 6 & 20 \\
\hline Karakteristik & Jumlah (orang) & Persentase $(\%)$ \\
\hline \multicolumn{3}{|l|}{ Penghasilan per bulan } \\
\hline$<\mathrm{Rp} 1.000 .000$ & 1 & 3 \\
\hline$>\operatorname{Rp} 1.000 .000-\operatorname{Rp} 2.000 .000$ & 16 & 46 \\
\hline$>\operatorname{Rp} 2.000 .000-\operatorname{Rp} 3.000 .000$ & 6 & 17 \\
\hline$>$ Rp $3.000 .000-\operatorname{Rp} 4.000 .000$ & 3 & 8 \\
\hline$>\operatorname{Rp} 4.000 .000$ - Rp 5.000.000 & 1 & 3 \\
\hline$>\operatorname{Rp} 5.000 .000-\operatorname{Rp} 6.000 .000$ & 3 & 9 \\
\hline$>\operatorname{Rp} 6.000 .000$ & 5 & 16 \\
\hline \multicolumn{3}{|l|}{ Pengalaman bertani (tahun) } \\
\hline $0-10$ & 20 & 57 \\
\hline $11-20$ & 7 & 20 \\
\hline $21-30$ & 5 & 14 \\
\hline $31-40$ & 3 & 9 \\
\hline \multicolumn{3}{|l|}{ Luasan lahan $\left(\mathrm{m}^{2}\right)$} \\
\hline $0-5.000$ & 22 & 63 \\
\hline $6.000-10.000$ & 8 & 23 \\
\hline $11.000-15.000$ & 1 & 3 \\
\hline $16.000-20.000$ & 2 & 5 \\
\hline $21.000-25.000$ & 1 & 3 \\
\hline $26.000-30.000$ & 1 & 3 \\
\hline \multicolumn{3}{|c|}{ Jumlah tanggungan keluarga (orang) } \\
\hline $0-5$ & 31 & 89 \\
\hline $6-10$ & 4 & 11 \\
\hline
\end{tabular}

Sumber :Data primer diolah, 2018 
Lampiran 3. Hasil Analsis CSI berdasarkan karyawan.

\begin{tabular}{|c|c|c|c|c|c|}
\hline No & Indikator & $\begin{array}{c}\text { Rataan tingkat } \\
\text { kepentingan }\end{array}$ & $\begin{array}{l}\text { Weight } \\
\text { factor } \\
\text { (WF) }\end{array}$ & $\begin{array}{c}\text { Rataan } \\
\text { tingkat } \\
\text { kepuasan }\end{array}$ & $\begin{array}{l}\text { Weight } \\
\text { Score } \\
\text { (WS) }\end{array}$ \\
\hline \multicolumn{6}{|c|}{ Tangible (berwujud) } \\
\hline 1 & $\begin{array}{l}\text { Kesesuaian gaji yang diberikan } \\
\text { gapoktan }\end{array}$ & 4,11 & $7,66 \%$ & 3,37 & 0,26 \\
\hline 2 & $\begin{array}{l}\text { Kesesuain bonus dan intensif yang } \\
\text { diberikan gapoktan }\end{array}$ & 4,20 & $7,82 \%$ & 3,63 & 0,28 \\
\hline 3 & $\begin{array}{l}\text { Kelengkapan fasilitas untuk mendukung } \\
\text { pekerjaan }\end{array}$ & 4,03 & $7,50 \%$ & 3,40 & 0,26 \\
\hline 4 & Kenyamanan ditempat kerja & 4,06 & $7,55 \%$ & 3,97 & 0,30 \\
\hline \multicolumn{6}{|c|}{ Realiability (keandalan) } \\
\hline 5 & Fleksibilitas peraturan ditempat kerja & 4,11 & $7,66 \%$ & 3,86 & 0,30 \\
\hline 6 & $\begin{array}{l}\text { Pelaksanaan penilaian terhadap kinerja } \\
\text { karyawan }\end{array}$ & 4,03 & $7,50 \%$ & 3,71 & 0,28 \\
\hline 7 & $\begin{array}{l}\text { Kemudahan berkomunikasi antar } \\
\text { karyawan dengan karyawan lainnya }\end{array}$ & 4,11 & $7,66 \%$ & 3,86 & 0,30 \\
\hline 8 & $\begin{array}{l}\text { Gapoktan memberikan manfaat dalam } \\
\text { meningkatkan kesejahteran karyawan }\end{array}$ & 4,23 & $7,87 \%$ & 3,71 & 0,29 \\
\hline \multicolumn{6}{|c|}{ Responsiveness (ketanggapan) } \\
\hline 9 & $\begin{array}{l}\text { Kejelasan dalam pemberian informasi } \\
\text { pada karyawan }\end{array}$ & 4,14 & $7,71 \%$ & 3,83 & 0,30 \\
\hline 10 & $\begin{array}{l}\text { Kecepatan gapoktan dalam menangani } \\
\text { permasalahan karyawan }\end{array}$ & 4,09 & $7,61 \%$ & 3,74 & 0,28 \\
\hline \multicolumn{6}{|c|}{ Assurance (Jaminan) } \\
\hline 11 & $\begin{array}{l}\text { Jaminan gapoktan terhadap kesehatan } \\
\text { dan keselamatan karyawan }\end{array}$ & 4,17 & $7,77 \%$ & 3,83 & 0,30 \\
\hline \multicolumn{6}{|c|}{ Empaty (empati) } \\
\hline 12 & Perhatian dari atasan & 4,20 & $7,82 \%$ & 3,89 & 0,30 \\
\hline 13 & $\begin{array}{l}\text { Kemudahan berkomunikasi dengan } \\
\text { atasan }\end{array}$ & 4,23 & $7,87 \%$ & 3,89 & 0,31 \\
\hline \multicolumn{2}{|r|}{ Jumlah } & 53,71 & $100 \%$ & 46,69 & $\mathbf{3 , 7 5}$ \\
\hline \multicolumn{2}{|r|}{ Rata-rata } & 4,13 & & $\mathbf{3 , 7 5}$ & \\
\hline \multicolumn{2}{|r|}{ CSI (\%) } & & & & $\mathbf{0 , 7 5}$ \\
\hline
\end{tabular}

Sumber :Data primer diolah, 2018 
Lampiran 4. Hasil analisis CSI berdasarkan anggota

\begin{tabular}{|c|c|c|c|c|c|}
\hline No & Indikator & $\begin{array}{l}\text { Rataan tingkat } \\
\text { kepentingan }\end{array}$ & $\begin{array}{l}\text { Weight } \\
\text { factor } \\
(\mathrm{WF})\end{array}$ & $\begin{array}{c}\text { Rataan } \\
\text { tingkat } \\
\text { kepuasan }\end{array}$ & $\begin{array}{l}\text { Weight } \\
\text { Score } \\
\text { (WS) }\end{array}$ \\
\hline \multicolumn{6}{|c|}{ Reliability (keandalan) } \\
\hline 1 & $\begin{array}{l}\text { Kemudahan dalam proses pendaftaran anggota } \\
\text { baru }\end{array}$ & 4,09 & $5,92 \%$ & 3,91 & 0,23 \\
\hline 2 & Kemudahan dalam melakukan simpan pinjam & 4,09 & $5,92 \%$ & 3,66 & 0,23 \\
\hline 3 & $\begin{array}{l}\text { Kesesuaian pengajuan pinjaman dengan } \\
\text { realisasi }\end{array}$ & 4,06 & $5,88 \%$ & 3,63 & 0,21 \\
\hline \multicolumn{6}{|c|}{ Responsiveness (ketanggapan) } \\
\hline 4 & $\begin{array}{l}\text { Kesigapan pengurus dalam memberikan } \\
\text { pelayanan }\end{array}$ & 4,09 & $5,92 \%$ & 3,60 & 0,21 \\
\hline 5 & $\begin{array}{l}\text { Kesigapan pengurus dalam menanggapi } \\
\text { permasalahan anggota }\end{array}$ & 4,09 & $5,92 \%$ & 3,54 & 0,21 \\
\hline 6 & Keceatan dan ketanggapan pelayanan Gapoktan & 4,09 & $5,92 \%$ & 3,49 & 0,21 \\
\hline \multicolumn{6}{|c|}{ Assurance (Jaminan) } \\
\hline 7 & $\begin{array}{l}\text { Kemampuan pelayanan Gapoktan terhadap } \\
\text { anggota }\end{array}$ & 4,03 & $5,84 \%$ & 3,40 & 0,20 \\
\hline 8 & $\begin{array}{l}\text { Engetahuan dan pelayanan yang baik dari } \\
\text { pengurus }\end{array}$ & 4,09 & $5,92 \%$ & 3,43 & 0,20 \\
\hline 9 & $\begin{array}{l}\text { Keberadaan Gapoktan dalam melaksanakan } \\
\text { pemasaran produk anggota }\end{array}$ & 4,09 & $5,92 \%$ & 3,14 & 0,19 \\
\hline \multicolumn{6}{|c|}{ Emphathy (Empati) } \\
\hline 10 & $\begin{array}{l}\text { Kemudahan berkomunikasi antara pengurus dan } \\
\text { anggota }\end{array}$ & 4,06 & $5,88 \%$ & 3,57 & 0,21 \\
\hline 11 & $\begin{array}{l}\text { Ketersediaaan waktu yang diberikan pengurus } \\
\text { terhadap anggota }\end{array}$ & 4,06 & $5,88 \%$ & 3,60 & 0,21 \\
\hline 12 & Perhatian pengurus terkait kepentingan anggota & 4,06 & $5,88 \%$ & 3,43 & 0,20 \\
\hline \multicolumn{6}{|c|}{ Tangiable (berwujud) } \\
\hline 13 & Transparansi keuangan & 4,11 & $5,96 \%$ & 3,74 & 0,22 \\
\hline 14 & $\begin{array}{l}\text { Kedekatan jarak anggota dengan lokasi } \\
\text { Gapoktan }\end{array}$ & 4,09 & $5,92 \%$ & 3,34 & 0,20 \\
\hline 15 & Kemudahan anggota dalam pembelian saprodi & 4,00 & $5.80 \%$ & 3,29 & 0,19 \\
\hline 16 & $\begin{array}{l}\begin{array}{l}\text { Kejujuran } \\
\text { pembayaran }\end{array} \\
\text { karyawan }\end{array}$ & 4,09 & $5,92 \%$ & 3,63 & 0,21 \\
\hline 17 & Kecepatan dalam penyediaan alat pertanian & 3,97 & $5,59 \%$ & 3,34 & 0,18 \\
\hline & Jumlah & 69,11 & $100 \%$ & 59,74 & $\mathbf{3 , 5 1}$ \\
\hline & Rata-rata & $\mathbf{4 , 0 7}$ & & $3, \mathbf{5 1}$ & \\
\hline & CSI $(\%)$ & & & & $\mathbf{0 , 7 0}$ \\
\hline
\end{tabular}

Sumber : Data primer diolah, 2018 
Lampiran 5. Hasil analisis Service Quality pada karyawan

\begin{tabular}{|c|c|c|c|c|}
\hline No & Indikator & $\begin{array}{l}\text { Kepentingan } \\
\text { (E) }\end{array}$ & $\begin{array}{l}\text { Kepuasan } \\
(\mathrm{P})\end{array}$ & $\begin{array}{l}\text { Skor } \\
(\mathrm{P}-\mathrm{E})\end{array}$ \\
\hline \multicolumn{5}{|c|}{ Tangible (berwujud) } \\
\hline 1 & Kesesuaian gaji yang diberikan gapoktan & 4,11 & 3,37 & $-0,74$ \\
\hline 2 & $\begin{array}{l}\text { Kesesuain bonus dan intensif yang diberikan } \\
\text { gapoktan }\end{array}$ & 4,20 & 3,63 & $-0,57$ \\
\hline 3 & Kelengkapan fasilitas untuk mendukung pekerjaan & 4,03 & 3,40 & $-0,63$ \\
\hline 4 & Kenyamanan ditempat kerja & 4,06 & 3,97 & $-0,09$ \\
\hline \multicolumn{5}{|c|}{ Realiability (keandalan) } \\
\hline 5 & Fleksibilitas peraturan ditempat kerja & 4,11 & 3,86 & $-0,26$ \\
\hline 6 & Pelaksanaan penilaian terhadap kinerja karyawan & 4,03 & 3,71 & $-0,31$ \\
\hline 7 & $\begin{array}{l}\text { Kemudahan berkomunikasi antar karyawan } \\
\text { dengan karyawan lainnya }\end{array}$ & 4,11 & 3,86 & $-0,26$ \\
\hline 8 & $\begin{array}{l}\text { Gapoktan memberikan manfaat dalam } \\
\text { meningkatkan kesejahteran karyawan }\end{array}$ & 4,23 & 3,71 & $-0,51$ \\
\hline \multicolumn{5}{|c|}{ Responsiveness (ketanggapan) } \\
\hline 9 & $\begin{array}{l}\text { Kejelasan dalam pemberian informasi pada } \\
\text { karyawan }\end{array}$ & 4,14 & 3,83 & $-0,31$ \\
\hline 10 & $\begin{array}{l}\text { Kecepatan gapoktan } \\
\text { permasalahan karyawan }\end{array}$ dalam menangani & 4,09 & 3,74 & $-0,34$ \\
\hline \multicolumn{5}{|c|}{ Assurance (Jaminan) } \\
\hline 11 & $\begin{array}{l}\text { Jaminan gapoktan terhadap kesehatan dan } \\
\text { keselamatan karyawan }\end{array}$ & 4,17 & 3,83 & $-0,34$ \\
\hline \multicolumn{5}{|c|}{ Empaty (empati) } \\
\hline 12 & Perhatian dari atasan & 4,20 & 3,89 & $-0,31$ \\
\hline 13 & Kemudahan berkomunikasi dengan atasan & 4,23 & 3,89 & $-0,34$ \\
\hline \multicolumn{2}{|c|}{ Jumlah } & 53,71 & 46,69 & \\
\hline
\end{tabular}

Sumber : Data primer diolah, 2018 
Lampiran 6. Hasil analisi Service Quality pada anggota

\begin{tabular}{|c|c|c|c|c|}
\hline No & Indikator & $\begin{array}{l}\text { Kepentingan } \\
\text { (E) }\end{array}$ & $\begin{array}{l}\text { Kepuasan } \\
(\mathrm{P})\end{array}$ & $\begin{array}{l}\text { Skor } \\
(\mathrm{P}-\mathrm{E})\end{array}$ \\
\hline \multicolumn{5}{|c|}{ Reliability (keandalan) } \\
\hline 1 & $\begin{array}{l}\text { Kemudahan dalam proses pendaftaran } \\
\text { anggota baru }\end{array}$ & 4,09 & 3,91 & $-0,17$ \\
\hline 2 & $\begin{array}{l}\text { Kemudahan dalam melakukan simpan } \\
\text { pinjam }\end{array}$ & 4,09 & 3,66 & $-0,43$ \\
\hline 3 & $\begin{array}{l}\text { Kesesuaian pengajuan pinjaman dengan } \\
\text { realisasi }\end{array}$ & 4,06 & 3,63 & $-0,43$ \\
\hline \multicolumn{5}{|c|}{ Responsiveness (ketanggapan) } \\
\hline 4 & $\begin{array}{l}\text { Kesigapan pengurus dalam memberikan } \\
\text { pelayanan }\end{array}$ & 4,09 & 3,60 & $-0,49$ \\
\hline 5 & $\begin{array}{l}\text { Kesigapan pengurus dalam menanggapi } \\
\text { permasalahan anggota }\end{array}$ & 4,09 & 3,54 & $-0,55$ \\
\hline 6 & $\begin{array}{l}\text { Keceatan dan ketanggapan pelayanan } \\
\text { Gapoktan }\end{array}$ & 4,09 & 3,49 & $-0,60$ \\
\hline \multicolumn{5}{|c|}{ Assurance (Jaminan) } \\
\hline 7 & $\begin{array}{l}\text { Kemampuan pelayanan Gapoktan terhadap } \\
\text { anggota }\end{array}$ & 4,03 & 3,40 & $-0,63$ \\
\hline 8 & $\begin{array}{l}\text { Engetahuan dan pelayanan yang baik dari } \\
\text { pengurus }\end{array}$ & 4,09 & 3,43 & $-0,66$ \\
\hline 9 & $\begin{array}{l}\text { Keberadaan Gapoktan dalam melaksanakan } \\
\text { pemasaran produk anggota }\end{array}$ & 4,09 & 3,14 & $-0,94$ \\
\hline \multicolumn{5}{|c|}{ Emphathy (Empati) } \\
\hline 10 & $\begin{array}{l}\text { Kemudahan berkomunikasi antara pengurus } \\
\text { dan anggota }\end{array}$ & 4,06 & 3,57 & $-0,49$ \\
\hline 11 & $\begin{array}{l}\text { Ketersediaaan waktu yang diberikan } \\
\text { pengurus terhadap anggota }\end{array}$ & 4,06 & 3,60 & $-0,46$ \\
\hline 12 & $\begin{array}{l}\text { Perhatian pengurus terkait kepentingan } \\
\text { anggota }\end{array}$ & 4,06 & 3,43 & $-0,63$ \\
\hline \multicolumn{5}{|c|}{ Tangiable (berwujud) } \\
\hline 13 & Transparansi keuangan & 4,11 & 3,74 & $-0,37$ \\
\hline 14 & $\begin{array}{l}\text { Kedekatan jarak anggota dengan lokasi } \\
\text { Gapoktan }\end{array}$ & 4,09 & 3,34 & $-0,74$ \\
\hline 15 & $\begin{array}{l}\text { Kemudahan anggota dalam pembelian } \\
\text { saprodi }\end{array}$ & 4,00 & 3,29 & $-0,71$ \\
\hline 16 & $\begin{array}{l}\text { Kejujuran karyawan saat melakukan } \\
\text { pembayaran }\end{array}$ & 4,09 & 3,63 & $-0,46$ \\
\hline 17 & Kecepatan dalam penyediaan alat pertanian & 3,97 & 3,34 & $-0,63$ \\
\hline & Jumlah & 69,11 & 59,74 & \\
\hline
\end{tabular}

Sumber : Data primer diolah, 2018 